\title{
Male Circumcision within the context of HIV prevention in India: a qualitative study conducted among young men in Chandigarh, India
}

\author{
Dr. Sanchit Kharwal ${ }^{1}$, Prof. Shalini Bharat ${ }^{2}$ \\ I(Public Health in Social Epidemiology, Tata Institute of social sciences, Mumbai, India) \\ ${ }^{2}$ (Centre for Health and social sciences, Tata institute of social sciences, Mumbai, India)
}

\begin{abstract}
Male circumcision has been advocated as an additional HIV prevention strategy but in India, it is not yet a part of the comprehensive HIV prevention package. In the Indian context male circumcision is strongly associated with specific religions and little is known about the socio-cultural and religious dimensions of this practice at the community level, the sensitivities attached to this practice, and its acceptance as a potential method of HIV infection prevention. The objectives of the study were to assess the level of knowledge and understanding of male circumcision among male youth of sexually active age group and to explore the practice of traditional male circumcision in a north Indian city. Data was collected by conducting 25 in-depth interviews, 5 key informant interviews and 2 focus group discussions. These interviews were tape recorded, transcribed, coded and analyzed using a qualitative software package. Results show that a majority of the respondents belonging to the non circumcising communities had limited understanding on male circumcision. Respondents from the circumcising community listed several benefits of doing male circumcision such as, better hygiene, prevention of infections, and enhancement of pleasure during sexual intercourse. The non circumcising community respondents considered male circumcision as a social stigma and carried the belief that approaching a traditional circumciser ('nai' or 'hajjam') to undergo circumcision will or may convert them to the religion of Islam. The acceptance of circumcision as a practice to improve health and prevent infections such as, HIV, looked seemingly negative among respondents from the non circumcising communities. Due to its strong association as an identifier of a particular religion, there are fears in adopting it and being discriminated or targeted as being a member of the minority community.
\end{abstract}

Keywords - Male circumcision, HIV, religion, social stigma, acceptance

\section{INTRODUCTION}

Having claimed millions of lives over the past several decades, Human Immunodeficiency Virus (HIV) is still a major public health burden across the globe ${ }^{[1]}$. As HIV epidemic persists and poses challenges to public health goals, countries need dedicated policies and actions to further strengthen the HIV prevention efforts. Thus, for national programs the prime focus should remain on identifying and promoting interventions that can effectively prevent new infections and thereby control the HIV epidemic. In the three Randomized Controlled Trials (RCT) conducted in the African region, Male Circumcision (MC) was seen to reduce chances of contracting HIV through vaginal intercourse by $60 \%$ in South Africa ${ }^{[2]}, 53 \%$ in Kenya ${ }^{[3]}$ and by $51 \%$ in Uganda ${ }^{[4]}$. Evidence also suggests that MC reduces the risk of acquiring sexually transmitted diseases (STDs) particularly ulcerative STI's like chancroid and syphilis ${ }^{[5]}$. Male circumcision is a surgical procedure of removing foreskin from the penis and is one of the oldest known surgical procedures that carry 'religious connotations ${ }^{{ }^{6}}{ }^{6]}$. Based on the compelling evidence that MC offers up to $60 \%$ protection from HIV, World Health Organization (WHO) and Joint United Nations Program on HIV/AIDS (UNAIDS) recommended that MC should be recognized as an additional HIV prevention strategy to reduce the risk of heterosexually acquired HIV infections in countries with high rates of heterosexual transmission of HIV infection and low rates of MC [7]. Currently in India male circumcision is not a part of the comprehensive HIV prevention package as advocated by government run National AIDS Control Program (NACP).

In the Indian context MC is traditionally and commonly practiced in certain minority communities such as Jewish and Islamic. Since it is not a practice followed by the Hindus who are in majority in the country, a majority of Indian men are non-circumcised. The association of MC with a key religious group that has a history of conflicts with the majority religion makes the topic of $\mathrm{MC}$ a sensitive one in India. However, regardless of religious affiliations circumcision is suggested and widely accepted as a medical intervention for children and even adults who suffer from disorders of prepuce such as phimosis, paraphimosis, and balanoposthistis ${ }^{[8]}$. There are limited studies assessing the community level perceptions about MC in the Indian context. The preliminary findings of the Indian Council of Medical Research (ICMR) task force study on community perspective of MC conducted by National AIDS Research Institute (NARI) had revealed that "male circumcision is a religious rite 
of circumcising communities; this belief is a common perception in the general population and religious sentiments are evident" ${ }^{[9]}$.

Religious beliefs and cultural systems will have a greater significance in determining attitudes towards MC. In particular, in the background of cultural and religious sensitivities, the topic of MC needs to be treated carefully so that barriers can be addressed to overcome resistance while promoting communal harmony. The main objectives of the study were to assess the knowledge, attitude, beliefs and practice of MC among traditionally circumcising and non-circumcising communities; and to explore the socio-cultural and religious beliefs associated with MC and the difference in its practice among traditionally circumcising and non circumcising communities of Chandigarh. The findings from this study are expected to contribute to a better understanding of the socio-cultural and religious underpinnings and sentiments around MC in the country in the context of the HIV epidemic.

\section{METHODOLOGY}

An exploratory research design using qualitative approach was used in this study as it helps to elicit the feelings, perceptions and opinions of the people in their own words and expressions allowing for gaining deeper insights into the phenomenon ${ }^{[10]}$. This study was conducted in Chandigarh - the Union Territory of the states of Punjab and Haryana.

\subsection{Sampling frame}

The study was carried out among male youth from two communities: the Muslim community in which MC is part of a religious practice (hereafter called the 'circumcising community') and non-Muslim communities (Hindu/Sikhs) in which MC is not practiced as a religious ceremony (hereafter called 'non-circumcising communities'). The sample for the research study comprised of male youth aged 19- 40 years, of which half of them belonged to the circumcising community and the other half were chosen from non circumcising communities. The sample also included key informants namely, Islamic Scholar (locally referred as Mufti - an Islamic Scholar who has the authority to issue legal opinions known as Fatwa), Muslim teachers at an Islamic school (locally referred as Madarsa), traditional circumcisers (locally referred as 'Nai' or 'Salamani Nai' Barbers who practice circumcision), and, medical doctor from a hospital in Chandigarh. The purpose of conducting key informant interviews was to understand the issue from a wider range of perspective and also to triangulate the findings in order to increase the quality of the data.

\subsection{Recruitment}

The non-probability purposive sampling was carried out at different sites within Chandigarh city keeping in mind the objective to select male youth from the two target communities. In order to facilitate entry into the Muslim community, officials at the two local mosques were first approached and after explaining the purpose of the study, they extended all support and assistance in conducting the interviews. The data was collected in the months of May and June, 2012, using three main qualitative research methods: in-depth individual interviews, key informant interviews (KIIs), and focus group discussions (FGDs). Separate guidelines were drafted for the method of data collection by KIIs, FGDs, and in-depth individual interviews. Themes included in the guidelines were based on a comprehensive review of existing literature on the subject ${ }^{[11,9]}$. This research study complied with ethical principles at all stages, respecting the dignity and rights of participants by ensuring confidentiality and anonymity, voluntary participation and providing informed consent.

\subsection{Data Analysis}

The data collected in the form of field notes and audio recordings of face to face interviews was first translated and transcribed from local languages of Hindi and Punjabi to English by the researchers. In enabling exploration and understanding the qualitative data, grounded theory approach given by Glaser and Strauss (1967) was used. Using the open coding method a selected random set of interviews were read and meaningful idea units were identified as 'codes'. Subsequently an extensive code list was prepared. Convergence among the codes with similar thematic content helped to identify 'themes'. ATLAS.ti (version 5) software was employed to manage the rich textual data. The prepared code list was used to code all the transcripts that were entered for analysis in the software. Careful analysis of the qualitative data highlighted a number of 'core themes'. A few additional sub-themes were also identified in this process. By employing the method of compare and contrast themes were grouped together and analyzed for similarities and differences between responses from men belonging to traditionally circumcising and non circumcising communities.

\section{RESULTS}

In total 25 respondents have participated in the In-depth interviews in addition to 5 key informants, and a total of 18 respondents who participated in 2 FGDs (Table 1, 2 and 3); adding to the total sample of 48. This 
section is organized as follows: The first section presents the socio-demographic profile of the respondents that includes background information on age, religion, education, marital status, and occupation and circumcision status of respondents. The second section presents the free listing data analysis and the last section presents the main findings under "core themes" and sub-themes that emerged from the data using the grounded theory analysis.

\subsection{Socio-demographic profile of respondents}

Table 1: Socio-demographic characteristics of study respondents who participated in In-depth interviews:

\begin{tabular}{|c|c|c|c|}
\hline Characteristic & Categories & Frequency & $\begin{array}{l}\text { Percentage } \\
(\%)\end{array}$ \\
\hline \multirow{3}{*}{$\begin{array}{l}\text { 1. Age in completed } \\
\text { years }\end{array}$} & $19-25$ & 11 & $44 \%$ \\
\hline & $26-34$ & 8 & $32 \%$ \\
\hline & $35-40$ & 6 & $24 \%$ \\
\hline Total & & 25 & $100 \%$ \\
\hline \multirow{3}{*}{ 2. Religion } & Hindu & 10 & $40 \%$ \\
\hline & Muslim & 13 & $52 \%$ \\
\hline & Sikh & 2 & $8 \%$ \\
\hline Total & & 25 & $100 \%$ \\
\hline \multirow{5}{*}{ 3. Education } & Primary & 7 & $28 \%$ \\
\hline & Secondary & 3 & $12 \%$ \\
\hline & $\begin{array}{l}\text { Higher } \\
\text { secondary }\end{array}$ & 8 & $32 \%$ \\
\hline & Graduate & 5 & $20 \%$ \\
\hline & $\begin{array}{l}\text { Post } \\
\text { graduate }\end{array}$ & 2 & $8 \%$ \\
\hline Total & & 25 & $100 \%$ \\
\hline \multirow{2}{*}{ 4. Marital status } & Unmarried & 14 & $56 \%$ \\
\hline & Married & 11 & $44 \%$ \\
\hline Total & & 25 & $100 \%$ \\
\hline \multirow{4}{*}{ 5. Occupation } & Student & 5 & $20 \%$ \\
\hline & Unemployed & 2 & $8 \%$ \\
\hline & $\begin{array}{l}\text { Self } \\
\text { employed }\end{array}$ & 8 & $32 \%$ \\
\hline & Service & 10 & $40 \%$ \\
\hline Total & & 25 & $100 \%$ \\
\hline \multirow{2}{*}{$\begin{array}{l}\text { 6.Circumcision } \\
\text { Status }\end{array}$} & Circumcised & 14 & $56 \%$ \\
\hline & $\begin{array}{l}\text { Non- } \\
\text { circumcised }\end{array}$ & 11 & $44 \%$ \\
\hline Total & & 25 & $100 \%$ \\
\hline
\end{tabular}

Table 2. Socio-demographic characteristics of key informants:

\begin{tabular}{|c|l|l|l|l|c|}
\hline $\begin{array}{c}\text { Informant } \\
\text { ID }\end{array}$ & Age & Education & Religion & $\begin{array}{c}\text { Marital } \\
\text { status }\end{array}$ & Occupation \\
\hline KI-1 & 72 & Primary & Muslim & Married & $\begin{array}{c}\text { Barber / Traditional } \\
\text { circumciser }\end{array}$ \\
\hline KI-2 & 25 & Primary & Muslim & Married & $\begin{array}{c}\text { Barber / Traditional } \\
\text { circumciser }\end{array}$ \\
\hline KI-3 & 30 & Doctorate & Muslim & Married & $\begin{array}{c}\text { Religious scholar } \\
\text { (Mufti) }\end{array}$ \\
\hline KI-4 & 38 & $\begin{array}{l}\text { Post } \\
\text { graduate }\end{array}$ & Muslim & Married & $\begin{array}{c}\text { Religious teacher in } \\
\text { a local mosque }\end{array}$ \\
\hline KI-5 & 30 & $\begin{array}{l}\text { Post } \\
\text { graduate }\end{array}$ & Sikh & Unmarried & Allopathic doctor \\
\hline
\end{tabular}


Table 3. Socio-demographic characteristics of FGD participants:

\begin{tabular}{|c|c|c|c|}
\hline Community & Characteristic & Categories & Frequency \\
\hline \multirow{11}{*}{$\begin{array}{c}\text { Non } \\
\text { circumcising }\end{array}$} & \multirow{2}{*}{$\begin{array}{c}\text { 1. Age in } \\
\text { completed years }\end{array}$} & $20-25$ & 5 \\
\hline & & $26-30$ & 3 \\
\hline & \multirow{2}{*}{ 2. Religion } & Hindu & 6 \\
\hline & & Sikh & 2 \\
\hline & \multirow{3}{*}{ 3. Education } & Secondary & 2 \\
\hline & & $\begin{array}{c}\text { Higher } \\
\text { secondary }\end{array}$ & 2 \\
\hline & & Graduate & 4 \\
\hline & \multirow{2}{*}{ 4. Marital status } & Unmarried & 6 \\
\hline & & Married & 2 \\
\hline & \multirow{2}{*}{ 5. Occupation } & Student & 1 \\
\hline & & Self employed & 7 \\
\hline \multirow{12}{*}{ Circumcising } & \multirow{3}{*}{$\begin{array}{l}\text { 1. Age in } \\
\text { completed years }\end{array}$} & $25-30$ & 6 \\
\hline & & $31-35$ & 3 \\
\hline & & $36-40$ & 1 \\
\hline & 2. Religion & Muslims & 10 \\
\hline & \multirow{4}{*}{ 3. Education } & Primary & 2 \\
\hline & & Secondary & 2 \\
\hline & & $\begin{array}{c}\text { Higher } \\
\text { secondary }\end{array}$ & 2 \\
\hline & & Graduate & 4 \\
\hline & \multirow{2}{*}{ 4. Marital status } & Unmarried & 2 \\
\hline & & Married & 8 \\
\hline & \multirow{2}{*}{ 5. Occupation } & Service & 4 \\
\hline & & Self employed & 6 \\
\hline
\end{tabular}

\subsection{Free listing (FL) data analysis}

FL was carried out with the objective of identifying the local religious and cultural terminologies used for MC and for the tools used in doing MC. In addition, local phrases and expressions used during the interviews were noted and linked with items and concepts related with circumcision. Analysis was done by reading the transcripts and identifying and counting the number of times an expression was used by a respondent to refer to a specific item. (See Table 4)

Table 4. Local terminologies used by Muslim respondents in the context of MC derived after FL analysis:

\begin{tabular}{|c|l|l|}
\hline Translated items & Local Terminologies & $\begin{array}{c}\text { Frequency } \\
\text { of usage }\end{array}$ \\
\hline \multirow{4}{*}{ Male Circumcision } & Sunnat, & 32 \\
\cline { 2 - 3 } & Khatna & 25 \\
\cline { 2 - 3 } & Sunnat ka tareeka & 6 \\
\cline { 2 - 3 } & Musalmaani & 4 \\
\cline { 2 - 3 } Traditional & Bithana & 1 \\
\hline \multirow{5}{*}{ circumcisers } & Nai & 15 \\
\cline { 2 - 3 } & Hajjam & 6 \\
\cline { 2 - 3 } & Khatna karne wala nai & 5 \\
\cline { 2 - 3 } & Hakeem karne wala & 1 \\
\cline { 2 - 3 } & Jarrah & 1 \\
\cline { 2 - 3 } & Nazu & 1 \\
\hline Remaining Pure & Paak saaf rehna & 15 \\
\hline
\end{tabular}




\begin{tabular}{|c|l|l|} 
Impure & Napaak & 10 \\
\hline $\begin{array}{c}\text { Inventor of } \\
\text { circumcision }\end{array}$ & Nabi ki sunnat hai & 4 \\
\hline God's Messenger & Nabi & 5 \\
\hline $\begin{array}{c}\text { Cutting of the } \\
\text { foreskin }\end{array}$ & Aaz-ul-khanaaz & 1 \\
\hline Logistics for Traditional Circumcision : \\
\hline Razor & Ustra & 6 \\
\hline $\begin{array}{c}\text { Ash of the earthen } \\
\text { oven }\end{array}$ & Chule ki raakh & 3 \\
\hline Foreskin holder & Jandri & 3 \\
\hline $\begin{array}{c}\text { Anaesthetic } \\
\text { Injection }\end{array}$ & Sunn ka teeka & 2 \\
\hline Bamboo needle & Baans ka sua & 2 \\
\hline
\end{tabular}

All the above listed local terminologies were mainly used by respondents from traditionally circumcising communities (Muslim) except from the two terms viz. 'sunnat' and 'khatna' that were used and understood by few respondents from traditionally non-circumcising communities.

\subsection{Main findings listed under core themes and sub themes}

a) Knowledge, beliefs and perceptions about MC: Under this theme five different subthemes emerged from the data. Findings are presented according to each subtheme.

i) $\mathrm{MC}$ as a religious practice: Almost all the respondents had heard of $\mathrm{MC}$ and a majority referred to it as 'sunnat' or 'khatna'. In the non-circumcising communities the usage was restricted to these two terms and some even used the term 'male circumcision' while respondents from circumcising community also referred to it as 'Mussalmani'. When asked to elaborate, a majority were able to define it in their own way mainly as the, "cutting of the foreskin of the penis". All respondents identified it as a religious practice that is followed among Muslims. Some of the respondents (5 of 12) from non circumcising communities were not aware of the specific terminologies used for MC, however once the procedure was described to them, they were able to recognize and link it with a specific religion i.e. Islam. Only two respondents both from non circumcising community were able to link MC with other circumcising communities as well such as, Jewish and Orthodox Christians. The majority (10 of 12) of the respondents from non circumcising communities had a limited understanding on MC. This was reflected in their responses when they were further asked to provide more details and elaborate the procedure, to which they replied with phrases such as "I only know this much... don't know more" (21 years old Hindu) or "I don't know the reasons for this" (30 years old Hindu). One Hindu respondent lacked understanding on the subject of MC and confused it with castration; his verbatim response is as stated below

"I think they (Muslims) do this so that somebody can't do rape. What I have seen on internet

is that a Muslim boy raped a girl and for that he was punished by cutting his penis" (22 years old Hindu)

On the other hand respondents from the circumcising community displayed adequate understanding of MC and revealed substantial information on the role of faith in performing MC. For them it is not just a religious ritual but has a deep rooted meaning in their religion and utmost importance is given to this practice. MC is known to them as "Sunnat" or "Khatna" and majority of them consider it as part of the religious ordainment.

"It is performed in Muslims not merely for benefit instead it is a way or a method which Jews, Christians and Muslims much respected messenger of God Hazrat-e-ibrahim has started. Than Hazrat-Mohammad-PBUH also ordered for this, so in reality the Muslims do circumcision for the reason that ALLAH and his messengers have given this order to us. Actually, because this is a religious practice, it is an order from God..." (30 years old Islamic scholar)

ii) MC as a symbol of being a Muslim: Among the non circumcising communities, $\mathrm{MC}$ is essentially seen as a religious practice which is only followed by Muslims. There is limited knowledge about the reasons for which it is practiced among circumcising communities. They feel that religion and culture is the primary reason for doing MC. Majority of the respondents replied that they do not possess sufficient knowledge on this subject and stated that "it's a value or custom among Muslims". Some respondents believe that MC is an identifier of Muslim religion and because of which it cannot be followed by other religions. Their responses are documented below: 
"No it can't be practiced by others except Muslims as it is specific to their culture. I think that by doing this we can come to know about their religion. If everybody started doing this than how will we come to know that who is a Muslim and who is Hindu? "(22 years old Hindu)

As per the responses received from a medical doctor and one of the non circumcising respondents, MC is still being seen as a mode of religious discrimination and a common point noted from both was that people from non circumcising communities who have undergone circumcision will tend to hesitate in disclosing their circumcision status as it is perceived to be a part of a Muslim identity. They said:

"Yes they might hesitate in disclosing their circumcision status mainly in those parts of the country where religious discrimination is still prevalent as I have already mentioned if a man is circumcised then it is assumed that he belong to Muslim community" (30 years old Sikh, Medical doctor)

However according to respondents from circumcising communities, MC does not only make oneself a Muslim and in order to become a true Muslim one has to accept the preaching's of Islam as well. According to one of the religious scholar as he states:

"Actually Islam is not just a word that one should do 'khatna' (circumcision) and becomes a Muslim. There are certain rules which one has to necessarily accept, there are views which had to be accepted from the heart like if you see all Christians are getting circumcised but still they are Christians, if only because one does 'khatna' and he is said to become Muslim then the entire world would have done 'khatna' and everyone would have become Muslim. It is a medical necessity also" (30 years old Islamic scholar)

iii) Beliefs about MC: The individual beliefs on male circumcision amongst the Muslim community respondents were associated strongly with religious ritual and practices. All of them considered circumcision as a religious obligation. The respondents from circumcising community emphasized that being uncircumcised makes them 'napaak' or impure and this sense of "purity" is linked to the belief that presence of foreskin helps to hold urine drops making them 'napaak' or impure. This belief of remaining 'paak' or Pure underlies the practice of MC as a ritual. According to the key informants, most of whom were religious scholars, in Islam, circumcision is synonymous with being "Pure" which is also about self respect and a part of the Muslim identity. A Muslim respondent says:

"The main reason to do this is because it brings purity... in Islam this is a part of our self respect (imaan)... in case if we are not pure then we will not remain a Muslim, so to become a true Muslim it is very important.... As we urinate so because of the foreskin some urine drops are left in the foreskin and we will not remain pure, so this is basically linked with purity (paak) - (39 years old Muslim)

iv) MC and its association with health and hygiene: Nearly all respondents from traditionally circumcising community associated $\mathrm{MC}$ with not just the religion and religious practice but with health and hygiene also. A few of the quotes that convey the importance of MC for hygiene and good health are documented below:

"Sunnat is a part of our 'Aaz -ul - khanaz' (cutting of the foreskin). In this the extra skin (Aaz) on the penis is cut and the same is shined, so that no dirt particle accumulates under the skin and the same leads in hygiene (safaai)" (30 years old Muslim)

In addition to associating MC with the notion of 'paak' or purity, some also cited its importance for disease prevention. MC was considered the reason for a low prevalence of HIV among Muslims.

"This is the message of 'Nabi' and we have to follow this, secondly it has health benefits, if you are not circumcised there will be dirt accumulation and rottenness due to which body is prone to many diseases, prevention from AIDS illness and other illnesses during intercourse (sambhog) when two bodies will mate" (38 years old Muslim).

v) $\mathrm{MC}$ is beneficial in various ways: Perceptions on sexual benefits: The understanding on sexual benefits of MC among the majority of the respondents from both traditionally circumcising and non circumcising communities was based on the perception that $\mathrm{MC}$ increases sexual pleasure and confidence during penetrative sexual intercourse. The presence of tight foreskin, it was pointed out makes penetrative sex difficult. Some of the respondents from non circumcising communities were not aware of the health benefits but acknowledged that MC offers benefits in one's sexual life. The participants from traditionally non circumcising communities expressed their views thus,

"No I haven't heard about the health benefits due to circumcision but yes I have heard that if someone had problem in penetration while intercourse then they can undergo this" (28 years old Hindu).

"Because of the absence of foreskin people enjoy sex life more because there is no sensation as compared to people who are not circumcised" (27 years old Sikh)

A respondent from traditionally non circumcising community who had undergone MC for treatment of phimosis expressed his views as: 
"I have undergone it myself. In case if someone has any problem of foreskin like infection, tight foreskin, tearing of foreskin during sex, and some also advise it for better hygiene. The health benefits are better hygiene, protection against HIV and STDs. It could result in sensitivity and dryness in the operated area during the initial days but no such harmful effects. I came to know about this through internet and after undergoing the procedure I personally felt that it results in erection for a longer period of time" (29 years old Hindu)

One of the respondents from traditionally non-circumcising community held a different perception on MC and its sexual benefit. According to him MC is a way to detect or prove the virginity of female sex partners. His viewpoint was not shared by any other respondent and possibly is part of the commonly held misbelieves about the religion and its practices. His response is documented below:

"In this religion, if you see it has a very deep reason which is that they don't trust ladies very much. Means after marriage they think that a girl should be a virgin....means... after marriage during intercourse the girl should bleed. Because at times if foreskin is not cut in boys then during intercourse the foreskin may rupture and it may bleed. So when I interacted with them and asked about this they said that if we do this then they can come to know whether a girl is virgin or not" (29 years old Hindu)

Among the circumcising men the perception was that circumcision offers sexual benefits in many different ways. It was considered particularly useful for enhancing sexual power and pleasure for the partner. The quote below illustrates this view.

"Yes, it has sexual benefit, Firstly in sex, pleasure (josh) increases; because of circumcision there is lot of tension (tanaav) inside the men and secondly your partner with whom sex is done enjoys very much, feels completely satisfied" (26 years old Muslim)

vi) MC and HIV related perceptions: It became evident from the data that for some, knowledge of HIV is fairly good but most of the respondents were not able to distinguish between HIV and AIDS. Many of them perceived AIDS as a dreaded and incurable illness and some have used metaphors like "lailaaj bimari" and "khatarnaak".

It was also observed that there is limited knowledge about the modes of HIV transmission and its prevention methods. Majority of the respondents from both traditionally circumcising and non circumcising communities had expressed its strong association with sex and some have emphasized on the immoral behavior on the part of the partner (bedmate). The association was also made with 'strangers' as partners.

"That's what I just told you that when we have impermissible relations (najayaz sambandh) with somebody. When our bedmate (humbistar) is wrong or is somebody who is not known to us (gair logon $k$ sath), from them it spreads" (40 years old Muslim)

With regard to the HIV prevention methods, majority of the respondents have heard about barrier methods and mentioned about the use of condom as an HIV prevention method. Importantly some of them maintained one should exercise 'self control'.

"Firstly one should have control on themselves, which is possible when one will not indulge in immoral behavior (galat sobat), should be committed to one partner and not give into sexual pleasures (sharirik sambhandh). Government has also introduced condoms for protecting oneself from AIDS" (40 years old Muslim)

Almost all of the respondents from both the communities lacked understanding on the role of MC in HIV prevention. Some of the respondents from circumcising community perceived that the role of MC in HIV prevention is linked to the collection of semen in the foreskin after having the sexual intercourse that further leads to germ accumulation.

"Yes it plays a vital role in protection of HIV, since when one has intercourse (sharirik sambandh), the fluid that comes out (Mani) gets collected under the foreskin which has germs and if the same is not cleaned than these germs remain inside the foreskin (khaal), it might cause infection, thus leading to increased chances of contracting HIV / AIDS" (30 years old Muslim)

b. Sources of Information on MC: While most respondents had heard of MC from different sources, the majority had not received comprehensive information on MC from a reliable source. Circumcision was described as an identifier for the Muslim community that is, it is symbolic of their membership to the religion, but it was also referred in a more casual way among peers of non-circumcising community respondents and used to label membership in the religion. The peer talk was also recognized as a source of misbelieves such as Muslims do MC in order to test the virginity of female partner and some loose talk. The data also revealed that male circumcision is often a subject which is laughed about as one of the respondents on being asked about the information source on MC reported that 'Usually this happens by ways of jokes about the other community (Muslims). I studied in a school which has lots of Muslims and during my childhood many of the Muslim students were teased by saying that "ye to katwa hai" (29 years old Hindu). 
For non-circumcising men the sources of information on MC primarily included either mass media such as TV and internet, or very importantly the presence of a Muslim friend in their social network or living in a Muslim neighborhood or studying in a school with Muslim students. For traditionally circumcising community, different information sources on MC included conversations with parents and discussions among family and friends during gatherings, religious scholars who preach about the religion and Holy books such as Quran Sharif. Male circumcision, it was revealed is a common topic of discussion within Muslim families signifying its relevance and importance for average community members.

c. Attitude and sentiments around MC in the context of HIV: The role of MC was explored with the respondents for its health benefits and more specifically in relation to HIV. Most of the informants from traditionally non circumcising communities expressed their worries by emphasizing on fears and cultural sentiments associated with MC. This also reflected their attitude towards MC and its acceptance as an HIV prevention strategy. They related this worry to the perception that circumcision is often a topic of laughter among them and that it is seen as a symbol of Islam, due to which they may suffer religious reparations. Therefore, undergoing circumcision may not be a desirable option in the context of any health issue such as, HIV. Three different kinds of fears were identified in the present study:

i) Fear of Rejection from one's own community: some of the informants sensed that circumcised men from the non circumcising communities might be neglected and disrespected in their own community. One of the respondents shared his view regarding MC by non circumcising communities as:

"One may have 'Fear of rejection' if you are from non-circumcising community, people without proper knowledge may not think that it has been done for some complication but may link you with being Muslim" (29 years old circumcised Hindu)

ii) Fear of being converted / identified as belonging to Muslim community: Some of the respondents mentioned incidents where traditionally non circumcising men approached traditional circumcisers to get circumcised but because of cultural implications and a fear of being labeled as a Muslim, refused to get it done from them and had undergone the procedure in a hospital. One such incident is mentioned below:

"... and the lady went home and she was told by her family that if you get your child's circumcision done by a Muslim 'nai' then he will also become a Muslim and so you will not get it done from him..." (35 years old Muslim)

iii) Fear of being mocked at: MC is often a subject that is joked about. Some respondents have expressed their views by reporting incidents where men from traditionally non circumcising communities who have undergone MC for some medical problem were teased and as a result those individuals will have a hesitation and fear to disclose their circumcision status to their own community members. One such incident is documented below:

"I have seen it in my childhood as well, we had a Rajput family in our neighborhood who followed Hinduism, even they had done it, I could not believe it back then, people used to tease them as well, that being a Hindu what have you done, what I mean is that circumcision was associated with Muslims, the people in the village used to tell him that he is now converted to a Muslim, he was our classmate, but here is where I have now seen the sure benefits of it, we used to read about it in the magazines, but people used to still relate it to religion, in spite of its benefit people never voluntarily came forward to accept it" (39 years old Muslim)

d. Acceptance of MC as an HIV prevention Strategy: Post the interview, a brief introduction was provided to the respondent on circumcision as a method to prevent HIV, and respondents were asked about its chances of acceptance by the community. Participants' expressed a mixed feeling on its acceptance as an HIV preventive strategy. While the respondents belonging to the non circumcising community expressed a seemingly negative acceptance to this attribute, on the other hand respondents from the circumcising community already had a predefined positive outlook because of the religious values associated. The uncertainty with regards to the acceptance of circumcision amongst the non circumcising communitoes, are clearly noted in the below quotes:

"No, they (non circumcising communities) will not accept it because if everybody started doing it then what is the difference left in being a Muslim or Hindu. But incase if it the only method of prevention of HIV then I think it should be done by all" (22 years old Hindu)

"Everybody will not accept it may be 50\% people might accept but 50\% may not because in India religion is always given prime importance and circumcision is only practiced by Muslims so others may not accept this. Only those who will consider these benefits to be important particularly those who are educated can accept it" (19 years old Hindu).

A few respondents have expressed doctors as an important medium of communication and for promoting its benefit. Few of the responses were:

"If it prevents from HIV then firstly we will contact a doctor about this...if the doctor says that circumcision has benefits and no harm than we can undergo but if a doctor says no than nobody will undergo circumcision"'(26 years old Hindu) 
Some respondents have expressed a low risk perception as a cause for not accepting MC as an HIV preventive strategy as they said:

"Even if we promote this in a country like India, it will not be accepted. Because in India it has a strong link with religion and your study shows only $60 \%$ protection, $40 \%$ is not sure, even if you remove the foreskin your semen still carries the virus, so there is no protection in that ...the new generation can accept this, but the old people cannot accept this...it is difficult to change the mentality of people and it will take some time and education can help in bringing this change" (28 years old Hindu)

Those who have expressed a positive attitude towards MC stated:

"If this has been proved scientifically in any survey, or anyhow, then this is possible, this can be given as an option that you can get circumcised just like in market you have condoms or it is advised to avoid multiple partners...then this can be advised. Yes definitely they will do accept it... there can be religious barrier, every place has different thoughts and for addressing these religious barriers you can go to them and make them understand that it prevents from HIV. In any community, there is nothing like you can't get circumcised, it's not written anywhere...circumcision is only done by Muslims if you think like this then it's not possible" (21 years old Hindu)

"Yes it will be acceptable provided the awareness is created in a proper manner. It can start with educated people who can understand its role in protection of HIV and the health and sexual benefits it offers. I feel it should be encouraged during male child birth itself" (29 years old Hindu)

e) The Practice of traditional male circumcision: In this section the results are presented based on several themes- some that were predetermined at the time of designing the interview guide and some new sub-themes were identified after reviewing and coding the interview transcripts. These include:

i) General information on traditional MC: Traditional MC is a method of doing circumcision using traditional tools, following certain religious rituals and is done by a religious or traditional circumciser. None of the respondents from traditionally non-circumcising communities were aware of the details about traditional MC, instead all of them were identified to have held a common misconception that traditional MC is done by religious priests (Maulwi) or a person from Mosque who read the Holy prayer (Namaaz), and the procedure is usually done in Mosques. The rest of the information presented in this section is based on the interviews with participants from circumcising community and key informants. Traditional MC was recognized as one of the oldest practices and an integral part of the Islamic culture. This practice being considered as an important occasion in the life of a Muslim, it was reported that some people celebrate it by organizing a small feast; however some respondents argued otherwise and stated that it is not a compulsion to conclude this event with a celebration. This was evident from the responses documented below:

"Normally when the kid is 2 to 3 days old "Khatna" is done, but there are many people who do it in a traditional way, call people, give them food, it is done like a function, but others don't make this a big function" (40 years old Muslim)

Traditional circumcisers: On enquiring about information on traditional circumcisers it was identified that in the earlier times usually in a village there used to be one family that belonged to caste of "Nai" and male members of these families used to do hair cutting, shaving and perform MC as an important responsibility. This profession is being continued in the family over the years and inherited from father to son and so on. On being asked about the evolution of this profession an informant replied:

“.... It can't be said from where this practice started but in actual this work was done by "Jarrah", these jarrah were meant to apply traditional medication (marham) on wounds (jhakham) or boils and blisters (phoda-phunsi) and these people (Nai) started helping them by giving hand in their work, so this real work used to be done by jarrah. They are a kind of Hakeem (faith healers) and they only, used to do this work... you can call them Hakeem but they don't do hazaamat (cutting and shaving). Because Nai's also started doing this job, they also started being called as with the same name otherwise hakeem, hazaam and jarrah are similar..." (38 years old Muslim, Religious teacher)

On being further enquired about information on traditional circumcisers a respondent said:

"They (traditional circumcisers) do not have a fixed place or a venue, where they can put up their business. They are normally a part of the hair cutting saloon. They also keep all their equipments at their home, one can go to their homes and get this done, but most of the people prefer calling these people in their homes to conduct the ritual" (22 years old Muslim)

Seasonal Trend of MC: In the study area researchers were able to locate and interview two traditional circumcisers who were practicing traditional $\mathrm{MC}$ in the area for more than seven years and fifty years respectively. During the interview with the traditional circumcisers it was identified that, the demand for 
circumcision normally increases during vacations, that is, at the beginning of summer season. This they said was irrespective of age constraint.

"Yes, we see it has to be some auspicious day. It should be a warm and easy day (naram garam). It should not be too hot neither too cold. From the term 'naram garam' I mean it should not be the monsoon season. Because during monsoon there is a fear of 'hausne' (possible infection), and during the rains the urine is hazardous and because of that we see a day when it is not too cold neither too hot" (40 years old Muslim).

However the other traditional circumciser stated that this practice was followed in the past, currently parents prefer to conclude this activity as soon as the child is born, keeping in mind the healing capacity and that the child at that age is not prone to the understanding of pain and other such feelings.

"Yes it was so earlier, but now as soon as the child was born he gets circumcised within few weeks, whether he is born during monsoon or in winter" (72 years old Muslim Traditional circumciser)

ii) Significance of traditional MC: In order to understand the significance of traditional MC and explore the reasons for circumcising by traditional ways respondents were asked on their ideologies associated with traditional MC. Some of the respondents also expressed a strong conviction that this practice of MC should be followed with prayers and reading verses from religious books. However some of the respondents argued, that this practice might be important but not a religious compulsion to perform MC. While interacting with one religious scholar it was noted that while Islam emphasizes on the benefits of MC, it is a secondary practice and does not compel a male born in a Muslim family to undergo MC, in order for one to be called a Muslim, he needs to comply with the principles of Islam and accept the preaching's of Allah / prophets from his heart, one cannot be termed as a pure Muslim only if he undergoes circumcision. Thus, although circumcision is generally associated with being Muslim, according to the religious scholars this practice does not make one a Muslim. Just the mere activity being undertaken is not enough to make one a Muslim. The verbatim is presented below:

"Practically speaking 'Khatna' in our religion (Islam) is important but it is not like very important. Instead it should be first accepted from Heart that God is one. Than who told about this thing is Hazrat Muhammad Sal-Allaho Alai he wassalam. On the day of justice the good and the bad will be known...all HIS angels will descend and it will be important to imbibe their teachings...have faith on them, all the messengers who have come up till now..; these are the actual fundamental things...it's ok that other practical identifying things are there, that is do khatna, but before this if these things are there (i.e faith on Angels and HIS messengers) and then alongside there is khatna also then it is like an identifier that he is a Muslim, Anyways it is compulsory but not such a big compulsion that an individual who...in straight and simple terms we say that he does not have faith on Allah and His teachings, but does khatna, then just by doing khatna he does not become a Muslim. Both the things are important" (30 years old Islamic scholar)

The significance of traditional MC is also evident from the fact that some members of the Muslim community, in the study area, irrespective of their educational background, prefer to conclude this practice through a traditional circumciser but in the presence of a doctor. This in turn reflects the importance of traditional circumcisers in the practice of MC. The traditional circumciser mentions an instance as quoted below

"Those who are knowledgeable in actual sense get it done by us (traditional circumcisers) only, because it is a sunnat in our religion, and it is the only method of 'sunnat', the way in which we do it, and others who believe in science and consider themselves more learned will say that anesthetic injection should be used and it would have been better if it was done in hospital, and there are some who are very educated like for instance there is a principal, a professor in $X Y Z$ who told me that he wants to get his son circumcised in presence of doctor but would like to get the 'sunnat' done by me only" (72 years old Muslim, Traditional circumciser).

iii) Procedure of traditional MC: Post interviewing a few traditional circumcisers; it became evident that the practice of circumcision is being followed in a specific pattern from one generation to another. The instruments used vary from the practice and skill of each circumciser. The views on importance given to factors such as hygiene, safety, sterilization and techniques that were mentioned by some respondents differed in each interview. The procedure of circumcision as described by one traditional circumciser below:

"We hold the foreskin with fingertips and then insert a 'salai' (needle made of Bamboo) inside that and then apply "jandri". We only use the sharp edge of the Ustra and not use any blade...instead we don't keep a blade and make a cut using our skilled hand ...very fine cut and do it...after being done on one kid we clean the 'ustra' with dettol and remove the blood stain from there and if other one is required to be done we use other ustra...we keep 3 ustra.... and in a week or within 2 days I boil them in water by adding dettol to it. After doing 
it we apply a medicine known as 'mercury kohroon': a laal dawaai followed by tying ash of the earthen oven on the operated area, there is one laal dawaai, one nilli dawaai and there is one pilli dawaai so basically this is mercury which are available in medical store. Instruments we use are Ustra, Gel (Xylocaine), jandri which is made of bamboo and needles made of bamboo that are used to hold the foreskin in correct manner"(72 years old Muslim, Traditional circumciser)

iv) Changes in traditional MC over time: Traditional MC has been practiced for decades in the study area. The demand for traditional MC increased over the years with an increase in the number of Muslim population, and also as a result of immigration. Traditional circumcisers were considered an important source of service providers because of cultural implications. These traditional circumcisers were found to be providing services not only limited to the study area but also in the neighboring states. However they are not formally trained and have acquired the knowledge of cutting practices from their fathers and forefathers. From the information collected on traditional MC from different sources, it became evident that over the years the practice has changed in a number of aspects as shown below but not limited to these alone.

Age at circumcision: Most of the respondents (9 of 12) from traditionally non circumcising communities have limited knowledge on age at which MC is carried out among circumcising communities. Compared to common understanding, it was identified that unlike Judaism, there is no fixed age for circumcision in Islam and majority of the children were circumcised before reaching the puberty.

"Islam does not have a fix age for this, this can even be done when they become an adult, but till such time they will remain impure, there is no upper age limit for this, just that it should be done as early as possible, within a week of birth is ideal, otherwise some people do it at the age of 2,3 or even 5 " (38 years old Muslim)

Majority of the respondents from circumcising community showed a preference for circumcising their children as early as possible and within a month of child's birth, the only exception to this is that if the child is weak only then it should be delayed and performed later. Several reasons for performing MC at an early age were cited by some of the Muslim respondents because of which they prefer their children to get circumcised during infancy. Respondents had said:

"It is said that the early you do it the better it is. Because in children they do not understand the pain sensation, they do not move their hands and legs... and because there is no movement it becomes easy to do and also it heals faster" (39 years old Muslim)

“...it's better to do it in childhood, so that the child doesn't feel much pain and doesn't even come to know and circumcision is seen as a symbol of Islam and for this reason it must be done in childhood so that the child also feels as a part of Islamic Culture" (30 years old Islamic scholar)

While interviewing a traditional circumciser, it was found that there exist certain differences in terms of the practice in rural and urban areas and some age restrictions. Whereas the children in urban areas are circumcised within a month of their birth but in some rural part, they get circumcised till the age of 10 years. Also another finding was made that these traditional circumcisers now refer the older aged children to get circumcised in hospitals because of the fear of encountering complications.

Use of Modern medicines in the traditional MC procedure: With modernization and advent of over the counter pharmaceutical products, traditional circumcisers tend to incorporate modern medical techniques while performing MC. They are aware of the use of local anesthetics, injections and also instruct the people who approach them for circumcision to visit a medical doctor and get the ointments and tetanus injections after the procedure. However, as evident from their responses the scientific role of maintaining sterilization and aseptic conditions seems unknown to them.

"earlier we used to get only cocaine, which we used to mix in the cream, which is used to cool the wound and when we perform circumcision the person feel nothing" (72 years old Muslim, Traditional circumciser)

"To make the skin Numb (sunn) I use a "pressure wali dawai" (possibly a lignocaine spray). I don't know its name and also I use a pin" (25 years old Muslim, Traditional circumciser)

"Once we do it for one kid, we clean the ustra (razor) with Dettol, clear the stains, and then if there is another one to perform, we use another ustra (razor), there are 3 ustra's (razors) lying, and twice in a week we even boil them in water adding dettol (antiseptic) to it"(72 years old Muslim, Traditional circumciser)

Preference for medical MC: On being asked about medical MC, almost all of the respondents (11 of 13) from traditionally circumcising communities know about medical MC and are aware of the fact that MC also happens in hospitals as a treatment for illnesses of the foreskin and also some Muslims prefer to get it done in hospitals by doctors as a part of their religious rite of MC. However among traditionally non-circumcising communities few respondents ( 4 of 12) were aware of medical MC and about the reasons for which it is carried out. 
"Nowadays most of the people are getting this done in the hospital, but the older people ... like the barber (nai) they used to do it earlier, there are few people also doing it" (35 years old Muslim)

"Yes it is done in hospitals also. Doctors only do this.. in our family all kids got circumcised by a doctor he was a BAMS doctor. Nowadays people are aware and use precaution to avoid any infection and even if they get it done by a traditional circumciser then after the procedure they take the child to a doctor to get the medicines" (39 years old Muslim)

While interviewing religious scholar it was noted that though they promote Islamic preaching's and are the face of Islam for their followers, they have themselves expressed a preference for getting MC done in hospitals and linked this change with modernization. According to him:

"Actually circumcision, till the time when there was no urbanization and it was not so developed and there was not much mobilization in between nations, there used to be one person or one family in the village who used to do this and who is called Nai. The only knowledge or qualification they have is the knowledge and training given by his father and forefathers they don't have any formal certification but there is nothing like it is done by Priests (maulwi)..Now a day's culture has developed so much that it happens in hospitals. Doctors are doing this...surgeons are doing this. Here also in our family, our children got circumcised by surgeons" (30 years old Islamic scholar)

This preference for medical MC was also mentioned in another interview with an allopathic doctor. His response is as below:

"Yes with increase in literacy rate and awareness, people have started preferring medical circumcision over traditional circumcision as it is a bloody and surgical procedure and I think it is not done in aseptic conditions by traditional circumcisers"30 years old Sikh, Medical doctor)

iv) Safety concerns about traditional MC: In some of the interviews Muslim respondents have expressed the safety concerns in doing MC in traditional ways and this raises their concerns about the safety of the child and influences them to get the child circumcised in hospitals. One of the Muslim respondent admitted that in villages it is done by untrained traditional circumcisers and they do it in aseptic conditions that expressed this as a reason to prefer medical MC.

"This is handled by untrained people in the village like a barber, they don't sterilize the razor. So some people catch infection, and it takes a little long time to heal. Otherwise people today are aware and they prefer doing it through some doctor, but still majority of the people in the villages get it done through traditional circumcisers, they have a razor to cut, wooden needles, which is a very old (desi) system, ash of the earthen oven etc .. it can be unsafe to apply, but today even after getting it done from them, people still visit doctors for medicines and other ointments, and many people bring their own blade" (39 years old Muslim)

"there are ill effects if an inexperienced person (Kam tajurbekar) does khatna for someone and if the foreskin is not properly cut or less cut or cut wrongly (tircha cut) the person can suffer from urine problems like, the urine (dhaar) might split, it can also damage the penis" (30 years old Muslim)

On probing about any challenges or errors encountered during their experience as traditional circumcisers, some of them notified a few instances, but declined to acknowledge the responsibility for the mistake; rather they attributed it to the carelessness of the person being circumcised.

\section{DISCUSSION}

The study investigated the knowledge, perceptions and beliefs about MC among young men from traditionally circumcising and non- circumcising communities in Chandigarh, and explored the practice of traditional MC in the circumcising community. The study also explored respondents' views about accepting MC as a potential method of HIV infection prevention and identified the socio-cultural and religious underpinnings and sentiments around MC which may act as facilitators or barriers in introducing MC as an HIV prevention method if it was ever considered any time in future in India. A majority of the respondents belonging to the non circumcising communities had limited understanding on MC but most of them knew circumcision as a symbol that differentiates Muslims from non-Muslims implying that practicing it carried the risk of being identified as belonging to that religious community. Misconceptions about MC among them were mainly due to lack of authentic sources of information on MC for general public. Due to religious implications the custom of "Sunnat" has to be performed by a traditional circumciser in order for it to be concluded in a religious manner. But many respondents from circumcising community did not necessarily link circumcision to be done by traditional circumcisers. Rather they were more open to approaching doctors. Another change in the practice of traditional $\mathrm{MC}$ is that although traditional circumcisers try to incorporate modern medical practices in their 
procedure of doing circumcision, however they are not formally trained and lack knowledge on sterilization and maintaining aseptic conditions while doing MC. But they are receptive about need for safety in procedure and are able to assess risks. The acceptance of circumcision among other communities, as a practice to improve health and prevent infections such as, HIV, looked seemingly negative amongst respondents from the non circumcising community. Due to its strong association as an identifier of a particular religion, there are fears in adopting it and being discriminated or targeted as being a member of the minority community. Those who expressed a positive outlook towards the acceptance of male circumcision feel that this could be best absorbed by those who are educated, and those who understand and prioritize on the benefits that male circumcision has to offer.

\subsection{Study limitations:}

Firstly, the focus of the study is only limited to men's perception about MC and women were not a part of this research study. This limits its validity as women's perception is crucial too in relation to sexual relationships and prevention of STIs. Secondly, the study was conducted in a specific region of India and included three different religions amongst which $\mathrm{MC}$ is only traditionally followed in one religion. The beliefs about and attitude towards MC from this study may be limited to a specific region and religions and may differ from the areas with a history of communal tensions.

\section{CONCLUSION AND RECOMMENDATIONS}

Beliefs and the deep rooted perceptions about male circumcision amongst men from non circumcising communities may pose a challenge for implementing a public health program on male circumcision as an HIV prevention measure.

\subsection{Recommendations:}

There is need for educating all communities about the correct meaning, practice and procedures of MC in order to remove the misperceptions and give correct knowledge about MC. As evident from the research study that traditional MC has certain drawbacks and might result in complications, it is therefore extremely important to identify and address the issue by providing the traditional circumcisers with necessary training and facilities as they are able to assess the risks and are receptive about the need for safety in the procedure. They can be partnered as stakeholders and trained for safer procedures or for promoting safety in MC. Future research using the quantitative methods and in other parts of the country is warranted to explore the acceptance about MC which may help in identifying the facilitators and barriers to strengthen the evidence on provision of safe MC services as an additional HIV prevention method.

\section{Acknowledgements}

Authors would like to thank all participants for sharing insights on this issue

\section{REFERENCES

WHO, HIV/AIDS Fact $\quad$ sheet $\quad N^{\circ} 360, \quad$ November 2012 accessed
(http://www.who.int/mediacentre/factsheets/fs360/en/index.html) on January $19^{\text {th }}, 2013$

[2] B Auvert, D Taljaard, E Lagarde, J Sobngwi-Tambekou, R Sitta, A Puren. Randomized, controlled intervention trial of male circumcision for reduction of HIV infection risk: the ANRS 1265 trial. PLoS Medicine, 2(11), 2005: e2.

[3] RC Bailey, S Moses, CB Parker, K Agot, I Maclean, JN Krieger, CF Williams, RT Campbell, JO Ndinya-Achola. Male circumcision for HIV prevention in young men in Kisumu, Kenya: A randomised controlled trial. Lancet, 369 (9562), 2007, 643656.

[4] RH Gray, G Kigozi, D Serwadda, F Makumbi, S Watya, F Nalugoda, N Kiwanuka, LH Moulton, MA Chaudhary, MZ Chen, NK Sewankambo, F Wabwire-Mangen, MC Bacon, CF Williams, P Opendi, SJ Reynolds, O Laeyendecker, TC Quinn, MJ Wawer. Male circumcision for HIV prevention in men in Rakai, Uganda: A randomised trial. Lancet. Vol. 369 (9562), 2007, 657-666.

[5] HA Weiss, SL Thomas, SK Munabi, RJ Hayes. Male circumcision and risk of syphilis, chancroid, and genital herpes: a systematic review and meta-analysis. Sexually Transmitted Infections. Vol. 82(2), 2006, 101-109

[6] P Aggleton. "Just a Snip"?: A Social History of Male Circumcision. Reproductive Health Matters 15 (29), 2007, 15-21.

[7] WHO \& UNAIDS. Male Circumcision for HIV Prevention: Research Implications for Policy and Programming WHO/UNAIDS Technical Consultation 6-8 March 2007 Conclusions and Recommendations (Excerpts). Reproductive Health Matters, Vol. 15 (29), 2007, 11-14

[8] International Classification of Diseases (ICD)-10, accessed from (http://www.icd10data.com/ICD10CM/Codes/N00-N99/N40N53/N47-/N47.1) on $10^{\text {th }} \mathrm{Feb}, 2013$

[9] S Sahay. Male Circumcision - a Passage from Cultural Rite to Biological Prevention. (National AIDS Research Institute) NARI Bulletin, Vol. 3 (3), 2012, 6-10

[10] D Silverman. The quality of qualitative health research: The open-ended interview and its alternatives. Social Sciences in Health, Vol. 4 (2), 1998, 104-118.

[11] Reproductive Health Matters, 15 (29), 2007

[12] A Strauss, J Corbin, 1998. Basics of Qualitative Research. Techniques and Procedures for Developing Grounded Theory (2 ${ }^{\text {nd }}$ ed.) (Newbury Park, Sage pub). 